\title{
Grade II meningiomas and Gamma Knife radiosurgery: analysis of success and failure to improve treatment paradigm
}

\author{
Charles A. Valery, MD, ${ }^{1,2}$ Matthieu Faillot, MD, ${ }^{2}$ Ioannis Lamproglou, $\mathrm{PhD},{ }^{1}$ \\ Jean-Louis Golmard, MD, ${ }^{3}$ Catherine Jenny, PhD, ${ }^{4}$ Matthieu Peyre, MD, PhD, ${ }^{2,6}$ \\ Karima Mokhtari, MD, ${ }^{7}$ Jean-Jacques Mazeron, MD, PhD, ${ }^{5,6}$ Philippe Cornu, MD, , ${ }^{1,2}$ and \\ Michel Kalamarides, MD, PhD ${ }^{1,2,6}$ \\ Unité de ${ }^{1}$ Radiochirurgie GK Region IDF, ${ }^{3}$ Recherche Clinique, ${ }^{4}$ Physique Médicale, and Service de ${ }^{2}$ Neurochirurgie, \\ ${ }^{5}$ Radiothérapie, and ${ }^{7}$ Neuropathologie, Hopital de la Pitié-Salpêtrière, AP-HP, Paris; and ${ }^{6}$ Sorbonne Universités, UPMC \\ Université Paris VI, Paris, France
}

\begin{abstract}
OBJECTIVE Grade II meningiomas, which currently account for $25 \%$ of all meningiomas, are subject to multiple recurrences throughout the course of the disease and represent a challenge for the neurosurgeon. Radiosurgery is increasingly performed for the treatment of Grade II meningiomas and is quite efficient in controlling relapses locally at the site of the lesion, but it cannot prevent margin relapses. The aim of this retrospective study was to analyze the technical parameters involved in producing marginal relapses and to optimize loco-marginal control to improve therapeutic strategy.

METHODS Eighteen patients presenting 58 lesions were treated by Gamma Knife radiosurgery (GKRS) between 2010 and 2015 in Hopital de la Pitié-Salpêtrière. The median patient age was 68 years (25\%-75\% interval: $61-72$ years), and the sex ratio (M/F) was 13:5. The median delay between surgery and first GKRS was 3 years. Patients were classified as having Grade II meningioma using World Health Organization (WHO) 2007 criteria. The tumor growth rate was computed by comparing 2 volumetric measurements before treatment. After GKRS, iterative MRI, performed every 6 months, detected a relapse if tumor volume increased by more than $20 \%$. Patterns of relapse were defined as being lo$\mathrm{cal}$, marginal, or distal. Survival curves were estimated using the Kaplan-Meier method, and the relationship between criterion and potential risk factors was tested by the log-rank test and univariable Cox model.
\end{abstract}

RESULTS The median follow-up was 36 months (range 8-57 months). During this period, 3 patients presented with a local relapse, 5 patients with a marginal relapse, and 7 patients with a distal relapse. Crude local control was $84.5 \%$. The local control actuarial rate was $89 \%$ at 1 year and $71 \%$ at 3 years. The marginal control actuarial rate was $81 \%$ at 1 year and $74 \%$ at 2 years. The distal control actuarial rate was $100 \%$ at 1 year, $81 \%$ at 2 years, and $53 \%$ at 3 years. Median distal control was 38 months. Progression-free survival (PFS) was $71 \%$ at 1 year, $36 \%$ at 2 years, and $23 \%$ at 3 years. Median PFS was 18 months. Lesions treated with a minimum radiation dose of $\leq 12$ Gy had significantly more local relapses than those treated with a dose $>12 \mathrm{~Gy}(p=0.04)$ in univariate analysis.

Marginal control was significantly influenced by tumor growth rate, with a lower growth rate being highly associated with improved marginal control $(p=0.002)$. There was a trend toward a relationship between dose and marginal control, but it was not significant $(p=0.09)$. PFS was significantly associated with delay between first surgery and GKRS $(p=0.03)$. The authors noticed few complications with no sequelae.

CONCLUSIONS In order to optimize loco-marginal control, radiosurgical treatment should require a minimum dose of $>$ $12 \mathrm{~Gy}$ and an extended target volume along the dural insertion. Ideally, these parameters should correspond to the aggressiveness of the lesion, based on genetic features of the tumor.

http://thejns.org/doi/abs/10.3171/2016.7.GKS161521

KEY WORDS stereotactic radiosurgery; atypical; grade II meningioma; marginal relapse; Simpson grade

ABBREVIATIONS 3D-SPGR = 3D-spoiled gradient recalled; FRT = fractionated radiation therapy; GKRS = Gamma Knife radiosurgery; PFS = progression-free survival; SRS = stereotactic radiosurgery; TGR = tumor growth rate; $W H O=$ World Health Organization .

SUBMITTED June 10, 2016. ACCEPTED July 18, 2016.

INCLUDE WHEN CITING DOI: 10.3171/2016.7.GKS161521. 
$\mathrm{R}$ ECENT modifications to the World Health Organization (WHO) 2007 and 2016 criteria defining Grade II meningioma have dramatically increased its frequency. Grade II meningioma currently accounts for about $25 \%$ of all meningiomas, which are the most frequent intracranial primary tumors in adults. ${ }^{17,22}$

Since the beginning of neurosurgery with Harvey Cushing, these tumors have represented a challenge for the neurosurgeon. Although they can be easily resected once or even several times with apparent total resection, they often recur at the original lesion site or at a distal location within the CNS. ${ }^{6,20,24}$ Previously, when tumor residue was left in place because of close or invaded critical structures (i.e., venous sinuses, cavernous sinus, cranial nerves), serial MRI was performed to detect potential progression, and when required, a second surgery or a conformal irradiation was planned. This came with the risk of possible side effects for the patient, such as edema, radionecrosis, or cognitive impairment. ${ }^{12,16}$

The emergence of Gamma Knife radiosurgery (GKRS) as an efficient and well-tolerated therapeutic alternative has transformed this paradigm, since treatment can be applied in various situations, namely as an adjuvant treatment, a treatment for relapses without prior irradiation, or a salvage treatment. . $^{10,11,13,25}$

Nevertheless, despite the local efficacy of GKRS, relapses are frequent and can progressively lead to a loss of control of the disease. These relapses may be local, marginal, or distal in nature. ${ }^{4,19}$ While distal relapses are part of the natural history of the disease, local and marginal failures might be related to technical issues, such as choice of dose and target. ${ }^{5,23}$

Although patterns of relapse have been described in several studies, few have focused on the parameters specific to marginal relapses. ${ }^{5}$

The ability of meningiomas to become more aggressive during the course of the disease has already been established..$^{15,18}$ Better knowledge about the behavior of these tumors, including their growth patterns and growth rate, should help clinicians to more accurately assess their malignancy and, therefore, to better design an optimized dosimetric plan.

Thus, the aims of this study were twofold: 1) to describe tumor growth patterns and growth rates in this cohort of patients, and 2) to analyze parameters contributing to loss of local and marginal control, in order to optimize treatment plans.

\section{Methods \\ Patients}

Eighteen patients with 58 lesions were treated at Hopital de la Pitié-Salpêtrière for Grade II meningioma between 2010 and 2015. The median patient age was 68 years (25\%-75\% interval: 61-72 years). The sex ratio $(\mathrm{M} / \mathrm{F})$ was 13:5. Six patients had 1 previous craniotomy, 8 had 2 procedures, and 4 had 3 procedures (Table 1). The median delay between surgery and GKRS was 3 years. No patients had a history of chemotherapy. All 18 patients underwent GKRS at the time of recurrence after prior surgery. Four of these 18 patients were classified as receiving salvage GKRS because they had already received
TABLE 1. Patient demographics

\begin{tabular}{lc}
\hline \multicolumn{1}{c}{ Variable } & Value \\
\hline No. of patients & 18 \\
\hline Median age in yrs $(25 \%-75 \%$ interval) & $68(61-72)$ \\
\hline Sex (M/F) & $13: 5$ \\
\hline $\begin{array}{l}\text { Median time in yrs btwn op \& 1st radiosurgery } \\
(25 \%-75 \% \text { interval) }\end{array}$ & $6(3.46-4.97)$ \\
\hline $\begin{array}{l}\text { No. of patients w/ previous irradiation (\%) } \\
\text { No. of patients w/ systemic antitumoral treatment }(\%)\end{array}$ & $0(0)$ \\
\hline No. of surgies per patient & 6 \\
\hline 1 surgery & 8 \\
\hline 2 surgeries & 4 \\
\hline 3 surgeries & \\
\hline
\end{tabular}

radiation on the target volume: 2 patients had undergone external-beam radiation therapy after the first surgery, and 1 patient had been given whole-brain radiation therapy for a hematological malignancy 10 years before surgery. The last patient was treated with stereotactic radiotherapy sessions after surgery. In addition, 2 patients previously received irradiation distant from the site of GKRS. Twelve patients underwent GKRS for the treatment of recurrent disease without previous irradiation. No patient received adjuvant GKRS.

\section{Lesions Characteristics}

Altogether, 58 lesions were treated in our cohort of 18 patients: 24 lesions were treated during a first session of GKRS in 18 patients, 23 lesions during a second session in 15 patients, and 6 lesions during a third session in 4 patients. In 1 patient, 4 lesions were treated during a fourth session, and 1 lesion was treated in a fifth session.

The lesions were located in the falx cerebri $(\mathrm{n}=30)$, convexity $(n=20)$, tentorium cerebelli $(n=3)$, and skull base $(\mathrm{n}=5$; Table 2$)$. The median lesion volume was 2.5 $\mathrm{cm}^{3}$ (range $0.1-14 \mathrm{~cm}^{3}$ ).

The lesions were classified as postoperative residues in 8 cases, lesions at the craniotomy site (surgical bed and dura mater) in 27 cases, lesions distant from the craniotomy site in 17 cases, and relapses after GKRS in 6 cases.

Tumor growth rate (TGR) before GKRS was computed by comparing 2 volumetric measurements (initial MRI and MRI on the day of GKRS) during the interval between these exams: TGR $=\mathrm{V}_{\mathrm{RS}}-\mathrm{V}_{\mathrm{i}} / \mathrm{t}_{\mathrm{RS}}-\mathrm{t}_{\mathrm{i}}(\mathrm{V}=$ volume; $\mathrm{t}$ = time; $\mathrm{RS}=$ radiosurgery $; \mathrm{i}=$ initial). The median TGR was $3.5 \mathrm{~cm}^{3} /$ year. TGR varied widely among lesions, ranging from 0.1 to $45 \mathrm{~cm}^{3} /$ year.

\section{GKRS}

A Leksell head frame was applied to the patient's head under local anesthesia, and 3D-spoiled gradient recalled (3D-SPGR) gadolinium-enhanced MRI and 1-mm thick CT scans were obtained. These images were codefined on GammaPlan software. Dosimetry was realized according to tumor volume, with a prescription dose of 14-16 Gy at $50 \%$ isodose.

Treatment plans were approved by a team consisting 
TABLE 2. Lesion characteristics

\begin{tabular}{lc}
\hline \multicolumn{1}{c}{ Variable } & Value \\
\hline No. of lesions & 58 \\
\hline Nature of lesions & 8 \\
\hline Postop residue & 27 \\
\hline Recurrence at craniotomy site & 17 \\
\hline Recurrence outside craniotomy site & 5 \\
\hline Marginal relapse of previous radiosurgery & 1 \\
\hline Local relapse of previous radiosurgery & 30 \\
\hline Tumor location & 20 \\
\hline Falx cerebri & 3 \\
\hline Convexity & 5 \\
\hline Tentorium cerebelli & $2.5(0.1-14)$ \\
\hline Skull base & $15(8-19)$ \\
\hline Tumor vol in cm ${ }^{3}$ (range) & $32(24-40)$ \\
\hline Dosimetry
\end{tabular}

of a neurosurgeon, a radiation oncologist, and a medical physicist.

\section{Pathology and Grading}

All patients were classified as having Grade II meningioma according to $2007 \mathrm{WHO}$ criteria.

\section{Imaging and Volumetry}

After the first GKRS treatment, iterative MRI was performed every 4-6 months to detect a relapse or a response of the treated lesion. A 3D contrast-enhanced, T1-weighted sequence was performed with 1.2-mm-thick isotropic slices. Each slice was delineated by a resident (M.F.) and a senior neurosurgeon (C.A.V.). Volumetry was assessed by GammaPlan software.

A growing lesion was defined as a relapse if the tumor volume increased by more than $20 \%$ when compared with its measurement on the day of treatment. ${ }^{18}$ Otherwise, the lesion was defined as controlled.

\section{Assessment of Relapse Patterns}

As described elsewhere, ${ }^{9,18,25}$ a relapse occurring inside the field of treatment ("in-field") was called a local relapse; when it occurred at the border of a previously treated lesion, it was considered to be a marginal relapse. Each treated lesion was assessed for local and marginal control, taking into account the delay between GKRS and last MRI.

A distal relapse was defined as a relapse occurring in a remote location outside the first treatment area. The first relapse was the only one taken into account. Out-of-field relapse (i.e., marginal plus distal relapse), distal relapse, and progression-free survival (PFS) were calculated for the patient and not by lesion.

\section{Statistical Analysis}

Study criteria included time to local relapse, time to distal relapse, time to marginal relapse, time to outfield relapse, and PFS. Each criterion was analyzed for survival analysis. Survival curves were calculated by the KaplanMeier method, and the relationship between each criterion and potential risk factor was tested by the log-rank test for qualitative variables and by the univariable Cox model for quantitative variables. The potential risk factors analyzed in this study were patient age, sex, tumor volume, minimum and maximum dose, previous radiotherapy, delay between surgery and GKRS, and tumor topography. Statistical computations were performed using the SAS V9.3 statistical package (SAS Institute Inc.).

\section{Results}

\section{Patterns of Relapse and Retreatment}

The median follow-up period was 36 months (range 8-57 months). Crude local control was $84.5 \%$.

During this time period, 3 patients presented with a local relapse, 5 with a marginal relapse, and 7 with a distal relapse (Fig. 1). Therefore, at the time of our analysis, $83.3 \%$ of patients had a relapse.

Among the patients in whom a recurrent lesion developed, 14 had a second GKRS; among them, 6 had a local relapse or a marginal relapse. In addition, 2 underwent both a surgery and fractionated radiation therapy (FRT); 1 underwent FRT and 1 was treated with chemotherapy. Of patients who underwent reoperation, 1 had a tumor that showed progression from Grade II toward Grade III.

\section{Survival Curves}

Survival curves were calculated to illustrate the time to local relapse, time to marginal relapse, time to distal relapse, time to outfield relapse, and PFS (local + marginal + distal; Fig. 2). The local control actuarial rate was $89 \%$ at 1 year and $71 \%$ at 3 years. The marginal control actuarial rate was $81 \%$ at 1 year and $74 \%$ at 2 years. The distal control actuarial rate was $100 \%$ at 1 year, $81 \%$ at 2 years, and $53 \%$ at 3 years. Median distal control was 38 months. The out-of-field control actuarial rate was $92 \%$ at 1 year, $68 \%$ at 2 years, and $42 \%$ at 3 years. Median out-of-field control was 33 months.

Finally, PFS was $71 \%$ at 1 year, $36 \%$ at 2 years, and $23 \%$ at 3 years. The median PFS was 18 months.

\section{Univariate Analysis}

Among parameters tested in a univariate analysis, lesions treated with a minimum dose of $\leq 12$ Gy had significantly more local relapses than those treated with a dose of $>12$ Gy ( $=0.04$; Fig. 3). However, TGR and tumor volume were not significantly associated with local control.

Marginal control was significantly influenced by TGR, with a lower TGR being highly correlated with improved marginal control $(\mathrm{p}=0.002)$. There was a trend toward a relationship between dose and marginal control, but it was not significant because of a lack of power $(p=0.09)$.

In addition, PFS was significantly associated with a delay between first surgery and GKRS $(\mathrm{p}=0.03)$.

\section{Complications}

Among this group of patients, we observed 2 patients 

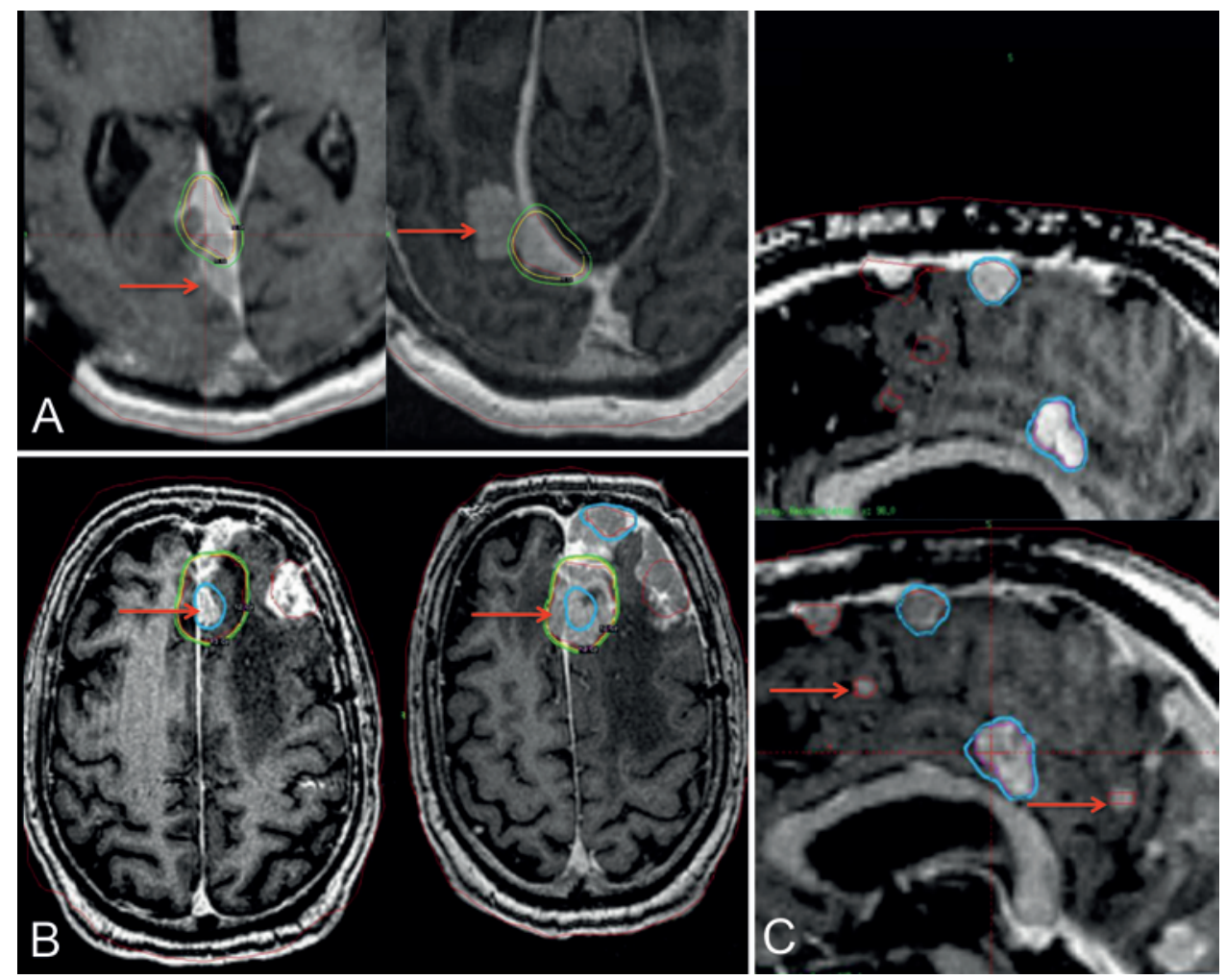

FIG. 1. Patterns of relapse. A: Marginal relapses at the border of a previously irradiated lesion (red arrows). B: Local relapse (red arrows), completely surrounding the previously treated lesion. C: Distal relapses (red arrows), far from the first treated lesion.

with radionecrosis, which was treated by corticosteroids; no surgery was required. There was also a patient who presented with a spontaneous hemorrhage and another with recurrent seizures. No long-term consequences were noticed.

\section{Discussion}

Meningiomas are typically benign lesions, but their ability to recur even decades after a good resection is well known. ${ }^{24}$ Grade II meningiomas have been recently redefined by new classification criteria that account for brain invasion as well as the usual histological features. With these new criteria, the incidence of Grade II tumors, which recur earlier and in a more diffuse manner than benign meningiomas, grows from $3 \%-4 \%$ to $20 \%-30 \% .^{17}$ Moreover, Grade II meningiomas are very heterogeneous and thus difficult to analyze in terms of PFS. Indeed, some display no mitoses and only brain invasion, while others are very aggressive histologically, with up to 19 mitoses/10 hpf (20 mitoses or more is a defining characteristic of Grade III meningiomas).

\section{Relapse Patterns}

The pattern of relapse for Grade II meningiomas is wide, and this heterogeneity is not well understood. Some tumors will only recur locally, while others will recur in a distal location. However, marginal relapses at the border of a previously treated lesion are a common occurrence for this group of tumors. . $^{1,4,5,10,19}$ Focused treatments, such as surgery and GKRS, can temporarily control new le- sions, but their high incidence and tendency to invade and progress along the dural structures will eventually prohibit long-term control of the disease. ${ }^{2}$ Some authors choose to study relapses according to surgical bed, whereas others focus on the pattern of relapses according to the radiosurgical field. We chose the latter approach. 919,26

Marginal lesions have been inconsistently described in the literature. A majority of authors pool together marginal and distal failures. ${ }^{1,3,5,26}$ Others define marginal failures as recurrent lesions occurring at the contact of a previously treated lesion ${ }^{18,19}$ or at a distance less than $2 \mathrm{~cm}$ from a previously treated tumor. ${ }^{9}$ In our study, we defined marginal failures as new nodules growing at the border of a previously treated lesion and found their occurrence to be associated with TGR.

It is commonly acknowledged that an efficient resection of a meningioma, even when benign, is one that requires removal of more tissue than the tumor itself. ${ }^{24}$ The resection must incorporate part of the dura mater surrounding the insertion to avoid early relapses.

Resection of cerebral parenchyma invaded by Grade II meningioma has not been evaluated in terms of recurrence. The occurrence of marginal relapses is possible evidence of some remaining tumor at the vicinity of its insertion that was not controlled by the radiosurgical prescription isodose. Following this idea, lack of local control might be related to the choice of dose, and marginal relapse might be due to inappropriate targeting. Therefore, improvements in both issues should require an optimized dose at reference isodose and a larger target than commonly used, ${ }^{23}$ i.e., a margin surrounding contrast enhancement. ${ }^{5,21}$ 

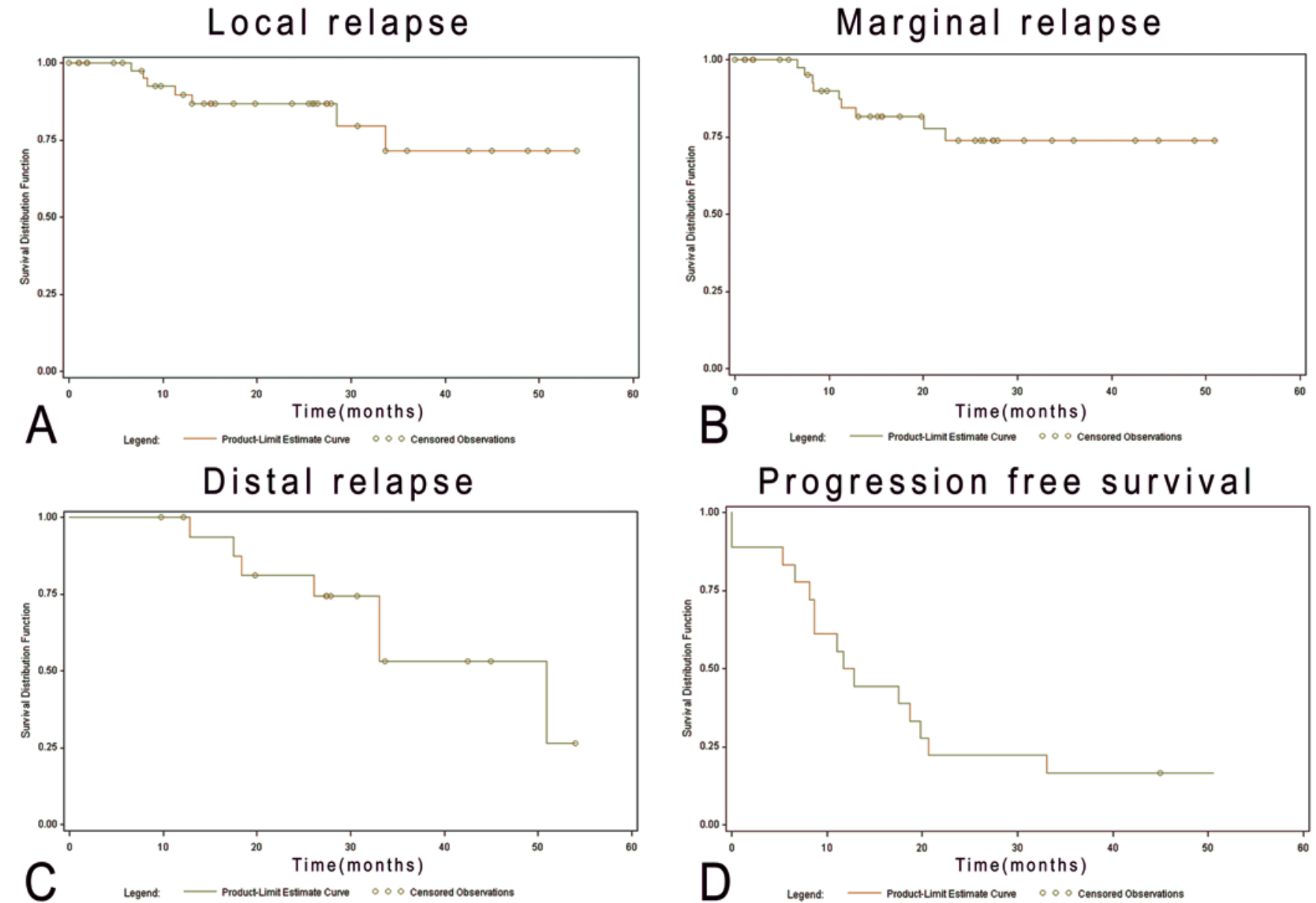

FIG. 2. Kaplan-Meier curves showing time without local relapse (A), time without marginal relapse (B), survival with no distal relapse (C), and PFS (D).

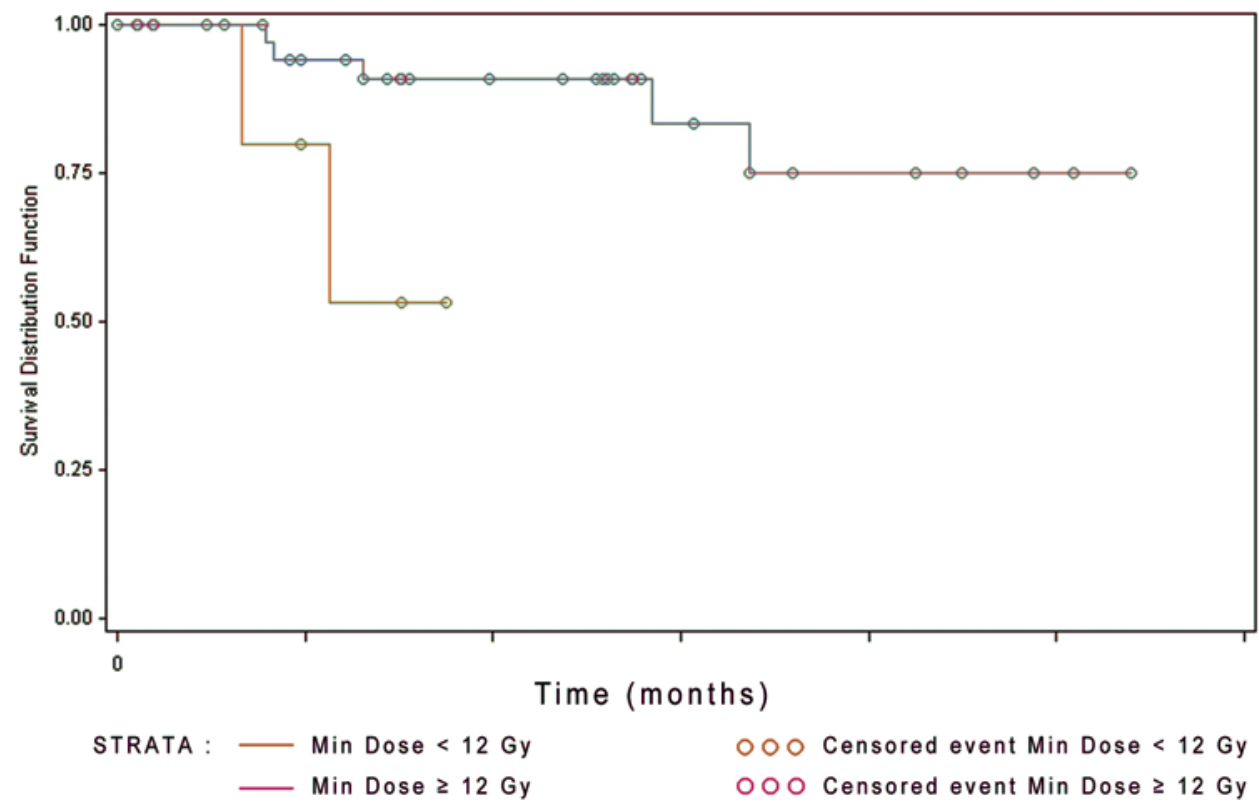

FIG. 3. Local control according to minimal dose. Kaplan-Meier curve showing a cutoff at $12 \mathrm{~Gy}$ for the minimal dose. A dose higher than 12 Gy was associated with improved local control $(p=0.04)$. 


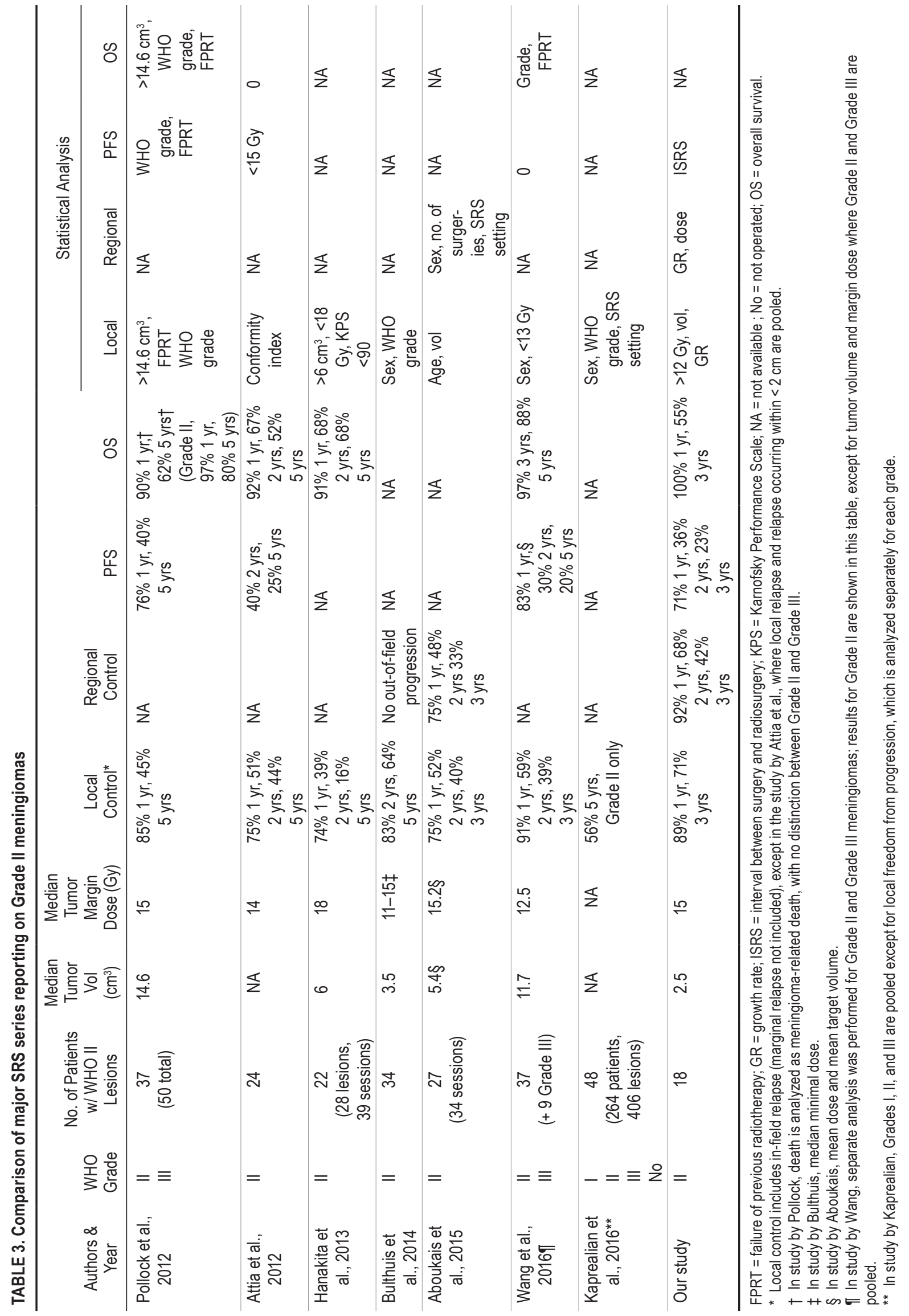


In our study, we considered marginal failures apart from distal relapses. In fact, marginal and local control should be grouped together for matters related to efficacy. Our results show that under a minimum delivered dose of $12 \mathrm{~Gy}$, the probability of local control is low. The local control rate and PFS were comparable to those previously published, $, 419,26$ but the median volume treated in our study was the lowest in the literature (Table 3). Among papers studying the relationship between minimum dose and local control, Wang et al. found a cutoff at $13 \mathrm{~Gy}$, and Attia et al. reported a cutoff at $15 \mathrm{~Gy} .{ }^{4,26}$ Sethi et al. reported that the prescription dose should not be lower than $16 \mathrm{~Gy} .{ }^{23}$

\section{Risk of Malignant Progression}

The ability of Grade II tumors to progress to Grade III during the course of their evolution is well established and is typically due to the accumulation of genetic events such as TERT promoter mutations and loss of $C D K N 2 A B$ expression. ${ }^{7,8}$ One unresolved issue concerns tumor grading at relapse. At the time of recurrence, it is unclear and unverifiable as to whether meningiomas are still Grade II or if they have transformed to Grade III. This possibility could explain the rapid growth (acceleration of growth) of some meningiomas at a distance from the site of GKRS or surgery. One approach for estimating malignancy could be to measure their growth rate before treatment. ${ }^{1}$ We analyzed this parameter in our study and found it to be significantly associated with risk of marginal relapse.

The risk of relapse could be more accurately predicted by analysis of specific gene alterations on the initial tumor that are used as biomarkers to identify meningiomas at risk for malignant transformation. Therefore, dosimetry could be tailored to fit with the potential malignancy of the tumor.

In addition, the significant number of relapses occurring at the site of craniotomy might justify performing a systematic irradiation of the surgical cavity bed after resection by GKRS or, if required, by stereotactic radiotherapy. In all cases, a close follow-up and the use of iterative procedures including surgery and GKRS are of great importance.

Study limitations include the following: 1) the low number of patients that may influence results of statistical correlations because of lack of power, 2) the potential for histological progression at the time of the relapse that may result in treating Grade III meningiomas rather than Grade II, and 3) our focus on individual target lesions rather than total tumor burden, which may affect our interpretation of data and not represent the global status of the disease.

\section{Conclusions}

In this study, we described patterns of relapse and tried to accurately analyze factors involved in local and marginal control of Grade II meningioma after GKRS. We found that a 12-Gy minimum radiation dose and TGR to be significantly associated with local and marginal control, respectively. Thus, an optimized radiosurgical treatment plan should require appropriate doses delivered to the lesion and larger target volumes, including dural insertion. Ideally, these parameters should correlate with the true aggressiveness of the lesion, based on genetic features of the tumor. A close follow-up and the use of various therapeutic approaches, including surgery, targeted therapies, and focused irradiation are of utmost importance.

\section{Acknowledgments}

We are grateful to Professor Guillaume Lot and to Drs. Marc Polivka, Chiara Villa, Annie Laquarrière, Françoise Chapon, Emmanuelle Lechapt-Zalcman, and Dominique Cazals-Hatem for their contributions to the study.

\section{References}

1. Aboukais R, Zairi F, Lejeune JP, Le Rhun E, Vermandel M, Blond S, et al: Grade 2 meningioma and radiosurgery. J Neurosurg 122:1157-1162, 2015

2. Aghi MK, Carter BS, Cosgrove GR, Ojemann RG, AminHanjani S, Martuza RL et al: Long-term recurrence rates of atypical meningiomas after gross-total resection with or without postoperative adjuvant radiation. Neurosurgery 64:56-60, 2009

3. Askoxylakis V, Zabel-du Bois A, Schlegel W, Debus J, Huber P, Milker-Zabel S: Patterns of failure after stereotactic radiotherapy of intracranial meningioma. J Neurooncol 98:367-372, 2010

4. Attia A, Chan MD, Mott RT, Russell GB, Seif D, Daniel Bourland J, et al: Patterns of failure after treatment of atypical meningioma with Gamma Knife radiosurgery. J Neurooncol 108:179-185, 2012

5. Bulthuis VJ, Hanssens PE, Lie ST, van Overbeeke JJ: Gamma Knife radiosurgery for intracranial meningiomas: Do we need to treat the dural tail? A single-center retrospective analysis and an overview of the literature. Surg Neurol Int 5 (Suppl 8):S391-S395, 2014

6. Gousias K, Schramm J, Simon M: The Simpson grading revisited: aggressive surgery and its place in modern meningioma management. J Neurosurg 29:1-10, 2016

7. Goutagny S, Nault JC, Mallet M, Henin D, Rossi JZ, Kalamarides M: High incidence of activating TERT promoter mutations in meningiomas undergoing malignant progression. Brain Pathol 24:184-189, 2014

8. Goutagny S, Yang HW, Zucman-Rossi J, Chan J, Dreyfuss JM, Park PJ, et al: Genomic profiling reveals alternative genetic pathways of meningioma malignant progression dependent on the underlying NF2 status. Clin Cancer Res 16:4155-4164, 2010

9. Hanakita S, Koga T, Igaki H, Murakami N, Oya S, Shin M, et al: Role of Gamma Knife surgery for intracranial atypical (WHO grade II) meningiomas. J Neurosurg 119:1410-1414, 2013

10. Hardesty DA, Wolf AB, Brachman DG, McBride HL, Youssef E, Nakaji P, et al: The impact of adjuvant stereotactic radiosurgery on atypical meningioma recurrence following aggressive microsurgical resection. J Neurosurg 119:475481,2013

11. Harris AE, Lee JY, Omalu B, Flickinger JC, Kondziolka D, Lunsford LD: The effect of radiosurgery during management of aggressive meningiomas. Surg Neurol 60:298-305, 2003

12. Jenkinson MD, Javadpour M, Haylock BJ, Young B, Gillard $\mathrm{H}$, Vinten J, et al: The ROAM/EORTC-1308 trial: radiation versus observation following surgical resection of atypical meningioma: study protocol for a randomised controlled trial. Trials 16:519, 2015

13. Kano H, Takahashi JA, Katsuki T, Araki N, Oya N, Hiraoka $\mathrm{M}$, et al: Stereotactic radiosurgery for atypical and anaplastic meningiomas. J Neurooncol 84:41-47, 2007

14. Kaprealian T, Raleigh DR, Sneed PK, Nabavizadeh N, Nakamura JL, McDermott MW: Parameters influencing local con- 
trol of meningiomas treated with radiosurgery. J Neurosurg 128:357-364, 2016

15. Krayenbühl N, Pravdenkova S, Sawyer JR, Stangeby C, Husain M: De novo versus transformed atypical and anaplastic meningiomas: comparisons of clinical course, cytogenetics, cytokinetics, and outcome. Neurosurgery 61:495-504, 2007

16. Mair R, Morris K, Scott I, Carroll TA: Radiotherapy for atypical meningiomas. J Neurosurg 115:811-819, 2011

17. Ostrom QT, Gittleman H, Fulop J, Liu M, Blanda R, Kromer C, et al: CBTRUS Statistical Report: Primary Brain and Central Nervous System Tumors Diagnosed in the United States in 2008-2012. Neuro Oncol 17 (Suppl 4):iv1-iv62, 2015

18. Peyre M, Zanello M, Mokhtari K, Boch AL, Capelle L, Carpentier A, et al: Patterns of relapse and growth kinetics of surgery- and radiation-refractory meningiomas. J Neurooncol 123:151-160, 2015

19. Pollock BE, Stafford SL, Link MJ, Garces YI, Foote RL: Stereotactic radiosurgery of World Health Organization grade II and III intracranial meningiomas: treatment results on the basis of a 22-year experience. Cancer 118:1048-1054, 2012

20. Porter KR, McCarthy BJ, Freels S, Kim Y, Davis FG: Prevalence estimates for primary brain tumors in the United States by age, gender, behavior, and histology. Neuro Oncol 12:520-527, 2010

21. Qi ST, Liu Y, Pan J, Chotai S, Fang LX: A radiopathological classification of dural tail sign of meningiomas. J Neurosurg 117:645-653, 2012

22. Rogers L, Barani I, Chamberlain M, Kaley TJ, McDermott M, Raizer J, et al: Meningiomas: knowledge base, treatment outcomes, and uncertainties. A RANO review. J Neurosurg 122:4-23, 2015

23. Sethi RA, Rush SC, Liu S, Sethi SA, Parker E, Donahue B, et al: Dose-response relationships for meningioma radiosurgery. Am J Clin Oncol 38:600-604, 2015

24. Simpson D: The recurrence of intracranial meningiomas after surgical treatment. J Neurol Neurosurg Psychiatry 20:22-39, 1957
25. Stafford SL, Pollock BE, Foote RL, Link MJ, Gorman DA, Schomberg PJ, et al: Meningioma radiosurgery: tumor control, outcomes, and complications among 190 consecutive patients. Neurosurgery 49:1029-1038, 2001

26. Wang WH, Lee CC, Yang HC, Liu KD, Wu HM, Shiau CY, et al: Gamma Knife radiosurgery for atypical and anaplastic meningiomas. World Neurosurg 87:557-564, 2016

\section{Disclosures}

The authors report no conflict of interest concerning the materials or methods used in this study or the findings specified in this paper.

\section{Author Contributions}

Conception and design: Valery, Kalamarides. Acquisition of data: Valery, Faillot, Lamproglou, Jenny. Analysis and interpretation of data: Valery, Faillot, Mokhtari, Kalamarides. Drafting the article: Valery. Critically revising the article: Valery, Peyre, Mazeron, Cornu, Kalamarides. Reviewed submitted version of manuscript: Valery, Kalamarides. Approved the final version of the manuscript on behalf of all authors: Valery. Statistical analysis: Lamproglou, Golmard. Study supervision: Valery.

\section{Supplemental Information \\ Previous Presentations}

This work was presented for oral plenary presentation on the 18th International Leksell Gamma Knife Society Meeting, Amsterdam, the Netherlands, May 18, 2016.

\section{Correspondence}

Charles A. Valery, Unité Radiochirurgie Ile de France, PitiéSalpêtrière Teaching Hospital, 47 bd de l'hopital, Paris 75013 , France. email: charles.valery@psl.aphp.fr. 